\title{
Truth in Tension: Reflections on Racism in Medicine
}

\author{
Ndidi I Unaka, MD, MEd ${ }^{1,2 *}$, Kimberly L Reynolds, MD³
}

'Division of Hospital Medicine, Cincinnati Children's Hospital, Cincinnati, Ohio; ${ }^{2}$ Department of Pediatrics, University of Cincinnati College of Medicine, Cincinnati, Ohio; ${ }^{3}$ Department of Pediatrics, University of Miami, Miller School of Medicine, Miami, Florida.

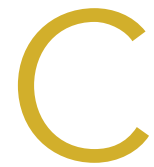

ore values should reflect our fundamental beliefs and serve as the building blocks of our behaviors and actions. Health systems across the United States define themselves by a myriad of guiding principles, which include patient-centeredness, dignity, respect, safety, and teamwork. On the surface, medicine's ties to such altruistic values make intuitive sense. However, as Black physicians, we are in a state of cognitive dissonance as we wrestle with healthcare's real identity and the principles it espouses. We know that within this psychological tension lies the truth: the US healthcare system was not designed to live up to these ideals. This truth is most evident in health inequities that exist among Black people and other marginalized communities of color. It is also the undeniable reality of Black physicians whose professional role is juxtaposed with recurring experiences that signal to us that we do not belong.

\section{SYSTEMIC RACISM, MISTRUST, AND HEALTH INEQUITIES}

Racism in healthcare, laid bare by the well-documented exploitation of Black people by the medical community, adds to the notso-subtle ways we are told our lives don't matter. ${ }^{1}$ This mistreatment has resulted in a deep mistrust of healthcare providers that is legitimate and real. The 40-year Tuskegee Syphilis Study is infamous for breaking trust via the deception of hundreds of Black men. The study participants with syphilis were denied treatment despite a known and available cure; an act both unconscionable and inhumane. As recently as the 1990s, a study sought to identify a genetic origin for aggressive behavior; however, enrollment was restricted to Black and Latino boys, and families were incentivized with money. Furthermore, the children were taken off all medications, kept overnight without their parents, deprived of water, subjected to hourly blood draws, and given fenfluramine, a drug known to be associated with precipitating aggressive behavior. ${ }^{1}$ The study design perpetuated the stereotype of Black males as perpetrators of violence-a distorted and biased perception that continues to cost Black people their lives. This sobering example illustrates that even in the era of institutional review boards, the welfare and protection of Black people who participate in research is by no means guaranteed.

*Corresponding Author: Ndidi I Unaka, MD, Med; Email: Ndidi.Unaka@cchmc .org; Telephone: 513-636-8354; Twitter: @NdidiUnaka.

Published online first June 25, 2020

Received: June 15, 2020; Revised: June 29, 2020; Accepted: June 19, 2020

(c) 2020 Society of Hospital Medicine DOI 10.12788/jhm.3492
The very notion of social determinants of health exposes the underbelly of institutional racism and its pervasiveness in our healthcare system. As Black physicians, we see the flawed healthcare system's disproportionate and devastating effects on patients who look like us: we have first-hand accounts as patients ourselves, and we have traversed the experiences endured by our loved ones. Broken trust and fractured care contribute to disparate rates of morbidity and mortality in Black men and women with cardiovascular disease, stroke, and diabetes. ${ }^{2}$ Black mothers have the highest rates of premature births and are three times more likely than White women to die from pregnancy-related complications. ${ }^{3}$ Black infants are two times more likely to die before their first birthday than are White infants. ${ }^{4}$ Children and adolescents from poor, predominantly Black and Latinx neighborhoods spend significantly more days in the hospital for various acute and chronic diagnoses than their counterparts from affluent, predominantly White neighborhoods. ${ }^{5}$ Not surprisingly, the COVID-19 pandemic's effects on the Black community read like lines memorized from the same old, tired, script ${ }^{\text {: }}$ staggering mortality rates, extreme poverty, food insecurity, alarming education inequities, and a widening digital divide. And, as Black pediatricians, we hold our breath as we wait until the coast is clear to fully assess the overwhelming damage to our children caused by the pandemic's tsunami.

\section{ACADEMIC MEDICINE AND OUR INVISIBLE WOUNDS}

In our roles as doctors, we experience first-hand the ills of academic medicine, an environment that poses significant challenges for those of us who are underrepresented in medicine (UIM). Despite an acute awareness of the need for Black physicians, little has changed over the past few decades. As of 2018, the percentages of Black or African American students who applied and were accepted to US medical schools were $8.4 \%$ and $7 \%$, respectively. ${ }^{7}$ Diversity gains in the acceptance and matriculation rates of medical students were noted across multiple demographic groups over the past 40 years; however, Black applicants were the exception. In fact, the number of Black men enrolled in medical schools is currently less than it was in 1978, a dismal statistic that underscores this issue. ${ }^{8}$ Only $5 \%$ of US physicians identify as Black or African American. ${ }^{7}$ Furthermore, in academia, while $64 \%$ of faculty are White, only $3.6 \%$ are Black or African American. ${ }^{7}$ But there is more to it than just the numbers. Diversity means nothing without an inclusive environment. As Black physicians, we understand the power of visibility, and our strong desire to cultivate a safe and 
inclusive environment for students, trainees, and other faculty is a large part of why we remain in academia. Nevertheless, the experience in academic medicine for Black physicians and other UIMs is commonly one of isolation.

Lack of inclusivity and feelings of isolation are common themes among Black physicians in academia. ${ }^{9}$ They are intensified by microaggressions, ${ }^{10}$ shards of glass that slowly cut at our self-concept, confidence, and resolve. We nurse the wounds from the ones hurled at our Black patients as well as the ones directed our way. They are the microassaults from the mother who requests that a different physician care for her child; the father who proudly displays a swastika tattoo as you examine his newborn infant in the nursery; or the directive to empty out the garbage when you walk into a patient's room. They are the microinsults from colleagues that convey our inferiority and associate our advancement with handouts because of our race; questions like, "How did you get that role?" and backhanded compliments such as, "You are so articulate," as we exceed their mediocre expectations. They are the microinvalidations, for example being constantly confused with the few other Black physicians in the hospital, which sends the message that we are invisible. Likewise, our minority tax —an underappreciated list of service-oriented expectations and responsibilities related to our UIM status_-is paid in full via the call to put our "otherness" on display for the sake of diversity and when we speak out against racism and bias because no one else will. There are limited opportunities to establish strong relationships with Black physician mentors, who are more likely to understand the needs and identify with the differential experiences of Black physician mentees. Examples of authentic and effective cross-race mentorship relationships built on trust and psychological safety are scarce, and their rarity exacerbates feelings of isolation and disillusionment among Black physicians. And rare sponsorship -in the form of high visibility recognition or career advancing opportunities-is conflated with veiled tokenism. This atmosphere breeds hypervigilance for Black physicians in academia. The weight of our actions and performance being judged not on an individual level, but rather as a reflection of our entire race, is a heavy load to bear.

\section{A CRITICAL JUNCTURE}

Our country is at a crossroads, with resounding calls to dismantle systemic racism in all its forms. The call is greatest for those of us who fight to heal our patients yet work in a healthcare system that perpetuates inequity. Radical steps are needed to rebuild the system and include:

- Working relentlessly towards health equity in all phases and facets of patient care. This must involve mandating data transparency, defining clear measures, and implementing processes that make equitable practices the default.

- Moving beyond one-dimensional diversity initiatives that focus on recruitment, and investing in strategies that promote the inclusion, retention, and advancement of UIM faculty along leadership and academic ranks.

- Establishing specific experiences, opportunities, and support structures for UIMs that include Black students, trainees, and faculty to combat isolation and foster inclusivity.

- Developing and implementing comprehensive trainee and faculty education focused on implicit bias in general, and structural racism, medical mistrust, and racial bias in healthcare in particular.

- Cultivating an antiracist environment in which true and authentic allyship is widespread and macro- and microaggressions are not silently endured by UIMs but are immediately and effectively addressed by all.

We must reconcile the dissonance that currently exists in our healthcare system between lofty ideals of racial equity and opportunity with actual practice-and as a result, honor the dignity and worth of the people who experience and work in it.

Disclosure: The authors have no conflicts of interest to disclose.

\section{References}

1. Washington HA. Medical Apartheid: The Dark History Of Medical Experimentation On Black Americans From Colonial Times to the Present. Doubleday Books; 2006.

2. Calvin R, Winters K, Wyatt SB, Williams DR, Henderson FC, Walker ER. Racism and cardiovascular disease in African Americans. Am J Med Sci. 2003;325(6):315-331. https://doi.org/10.1097/00000441-200306000-00003

3. Petersen EE, Davis NL, Goodman D, et al. Vital signs: pregnancy-related deaths, United States, 2011-2015, and strategies for prevention, 13 states, 2013-2017. MMWR Morb Mortal Wkly Rep. 2019;68(18):423. https://doi. org/10.15585/mmwr.mm6818e1

4. Centers for Disease Control and Prevention. Reproductive Health. Maternal and Infant Health. Infant Mortality Rates by Race and Ethnicity, 2016. Accessed June 6, 2020. https://www.cdc.gov/reproductivehealth/maternalinfanthealth/infantmortality.htm

5. Beck AF, Anderson KL, Rich K, et al. Cooling the hot spots where child hospitalization rates are high: a neighborhood approach to population health. Health Aff. 2019;38(9):1433-1441. https://doi.org/10.1377/hlthaff.2018.05496

6. Yancy CW. COVID-19 and African Americans. JAMA. 2020;323(19):18911892. https://doi.org/10.1001/jama.2020.6548

7. Diversity in Medicine: Facts and Figures 2019. Association of American Medical Colleges. Accessed June 6, 2020. https://www.aamc.org/data-reports/ workforce/report/diversity-medicine-facts-and-figures-2019

8. Altering the Course: Black Males in Medicine. Association of American Medical Colleges; 2015.

9. Campbell KM, Rodríguez JE. Addressing the minority tax: perspectives from two diversity leaders on building minority faculty success in academic medicine. Acad Med. 2019;94(12):1854-1857. https://doi.org/10.1097/ ACM.0000000000002839

10. Freeman $L$, Stewart $H$. Microaggressions in clinical medicine. Kennedy Inst Ethics J. 2018;28(4):411-449. https://doi.org/10.1353/ken.2018.0024 